\title{
Stented Ureterovesical Anastomosis in Renal Transplantation: Does it Influence the RATE of URINARY Tract InfECTIONS?
}

\author{
Z. Mathe ${ }^{1}$, J. W. Treckmann ${ }^{1}$, M. Heuer ${ }^{1}$, A. Zeiger ${ }^{1}$, S. Sauerland ${ }^{2}$, O. Witzke ${ }^{3}$, A. Paul ${ }^{1}$ \\ ${ }^{1}$ Department of General-, Visceral-and Transplantation Surgery, University Hospital of Essen, University Duisburg-Essen, Germany \\ 2Institute for Research and Operative Medicine, University of Witten/Herdecke, Campus Cologne, Germany \\ ${ }^{3}$ Department of Nephrology, University Hospital of Essen, University Duisburg-Essen, Germany
}

\begin{abstract}
Objective: Our objective was to evaluate the impact of routine use of double-J stents on the incidence of urinary tract infection after renal transplantation.

Methods: We conducted a retrospective-comparative single-centre study in 310 consecutive adult deceased donor kidney recipients transplanted from 2002 to 2006. Patients were divided in two groups, with or without urinary stent implantation. To evaluate the predictive factors for UTI, donor and recipients preand post-transplantation data were analysed. Early urological complications and renal function within 12 months of transplantation were included as well.

Results: A total of 157 patients were enrolled to a stent (ST) and 153 patients to a no-stent (NST) group. The rate of urinary tract infection at three months was similar between the two groups (43.3\% ST vs. $40.1 \%$ NST, $\mathrm{p}=0.65)$. Of the identified pathogens Enterococcus and Escherichia coli were the most common species. In multivariate analysis neither age nor immunosuppressive agents, BMI or diabetes seemed to have influence on the rate of UTI. When compared to males, females had a significantly higher risk for UTI $(54.0 \%$ vs. $33.5 \%)$.

Conclusion: Prophylactic stenting of the ureterovesical anastomosis does not increase the risk of urinary tract infection in the early postoperative period.

Key words: kidney transplantation, anastomosis, ureterovesical stent, urinary tract infection, sepsis
\end{abstract}

\section{INTRODUCTION}

Urinary tract infections (UTI) are the most common infectious complications in patients receiving renal transplantation for end stage kidney disease $[1,2]$. UTI could be associated with an increased morbidity and mortality risk, can worsen the graft and patient survival in renal transplant recipient [3, 4]. A significant proportion of kidney transplant recipients with UTIs may develop acute pyelonephritis, which is an independent risk factor for deterioration of graft function [5].

Some recent studies suggest routine prophylactic stenting of ureterovesical anastomosis at the time of graft implantation to reduce the incidence of early postoperative major urologic complications, as urinary leaks and stenosis [6-8]. Others advocate the use of stent only in selective, difficult cases while routine stenting could be associated with specific complica- tions as haematuria, migration, malposition or complications of removal $[9,10]$.

It has been shown, that urinary stenting could lead to a significant increase of infections of lower and upper urinary tract in immunocompromised patients [11]. Although, whether universal routine stenting of the ureteroneocystostomy is a real risk factor for the development of severe urinary tract infection (UTI) after renal transplantation is still controversial. Therefore, to help further clarify this issue, we compared the frequency of UTI in our cohort of deceased donor kidney transplant recipient transplanted with or without ureteric stent implantation.

\section{PATIENTS AND Methods \\ STUdy POPULATION}

This is a retrospective, observational study of deceased donor renal allograft recipients who were consecutively transplanted at University Hospital Essen, Germany between January 2002 and December 2006 $(\mathrm{n}=310)$. Data for this study were obtained from our transplant database and review of electronic and paper-based medical records. All adult ( $>18$ years) deceased donor kidney transplantations, except combined multiorgan transplants were considered. Living donor transplantations were not included in the study. Transplant procedures were performed in accordance with standard techniques. Double-J ureteral catheters were placed intraoperatively per the surgeon's discretion based on ureter, bladder and anastomotic characteristics until June 2004 and on routine basis thereafter. 157 patients were enrolled to a stent- (ST) and 153 patients to a no-stent (NST) group. Recipient and donor demographic and laboratory data, at the time of transplantation and afterwards were reviewed.

Urinary tract infection was defined as the patient having one of the following symptoms dysuria, fever, urgency, frequency, suprapubic tenderness, and positive urine culture with $\geq 10^{5}$ microorganism $/ \mathrm{cm}^{3}$ or two of the above signs and pyuria $\left(>\mathrm{WBC} / \mathrm{mm}^{3}\right)$ or $<105 \mathrm{mi}-$ croorganism $/ \mathrm{cm}^{3}$ if patient was on antibiotics.

Intravenous cefazoline ( $2 \mathrm{~g}$ ) was given once perioperatively within 30 minutes prior to skin incision and repeated once when operation exceeded 3 hours. A dose of single strength trimetoprim/sulfametoxazole (TMP/SMX) was started on day 2 or 3 and continued every second day for four to six months. The Foley 
catheter was removed on postoperative days 4-7. Urine samples were collected by aseptic technique. All stents were removed by cystoscopy under aseptic conditions 4-6 weeks after transplantation. Antibiotic prophylaxis was not given before removing the stents. The Double-J catheter tips were cultured for bacteria and fungi.

Immunosuppression consisted of methylprednisolone $(500 \mathrm{mg}$ given intraoperatively, followed by sequential tapering to daily oral prednisone $30 \mathrm{mg}$ by one week, $10 \mathrm{mg}$ at one month and $5 \mathrm{mg}$ at $6-12$ months), mycophenolate-mofetil ( $2 \mathrm{~g} / \mathrm{d}$ postoperatively with dose adjustment for side effects), calcineurininhibitors (tacrolimus or cyclosporin-A started within 24 hours after surgery) and/or IL-2 receptor blockers (basiliximab, daclizumab). Estimated glomerular filtration rate (eGFR) was calculated using the MDRD formula:eGFR $(\mathrm{ml} / \mathrm{min} / 1.73 \mathrm{~m} 2)=186 \times$ CrS-1.154 $\mathrm{x}$ age- $0.203 \times 0.742$ (if female). „Extra risk“ recipients were defined as recipients older than 60 years or older than 50 years with at least one of the following risk factors: coronary heart disease,peripheral arterial disease (PAD, grade IIa or higher), diabetes mellitus [12]. Patients with findings suggestive of UTI were hospitalized for further work-up and treatment, if necessary.

\section{URETEROVESICAL IMPLANTATION}

The technique of the ureteroneocystostomy consisted of an end-to-side extravesical implantation of the ureter onto the anterior bladder wall, modified from the Lich-Gregoire procedure. In summary, a cc. $1.5 \mathrm{~cm}$ incision of detrusor was made on the posterolateral aspect of bladder, followed by sharp dissection of mucosa. The anastomosis was constructed between the spatulated distal donor ureter and a small bladder mu- cosal nick made after myotomy incision. A watertight mucosa-to-mucosa anastomosis, using $5 / 0$ or $6 / 0 \mathrm{ab}-$ sorbable running sutures was performed of the spatulated ureter to a distal mucosal opening, followed by the creation of submucosal tunnel by approximation of seromuscular layers using absorbable sutures.

\section{STATISTICAL ANALYSIS}

Data are given as counts (with percentages) or mean values (with SDs). Medians (with interquartile ranges [IQR]) are reported for non-normally distributed data. For univariate comparisons between the groups, we used chi-square or Fisher's exact test for categorical variables, and by Student's t or Mann Whitney rank sum test for continuous variables. Box plots follow the standard format as used by SPSS (Version 15). P-values less than 0.05 were accepted as statistically significant.

We used multivariable analysis in order to adjust for baseline imbalances between the groups. A logistic regression model was developed to predict urinary tract infection, using various demographic and medical variables as covariates. By stepwise backward selection, non-predictive variables were eliminated using a threshold of $p<0.1$. The explanatory power of the final model was examined by calculating Nagelkerke's $\mathrm{R}^{2}$ coefficient, which ranges between 0 (no predictive power at all) and 1 (UTI incidence predictable with $100 \%$ certainty).

\section{RESULTS}

During the study period 310 patients were eligible for analysis. Patient characteristics and transplantation related data are summarized in Table 1. All patients were

Table 1. Baseline characteristics of the two group of recipients.

\begin{tabular}{|c|c|c|c|}
\hline & ST group & NST group & $P$ value \\
\hline No. of pts. & $157(50.6 \%)$ & $153(49.4 \%)$ & - \\
\hline Mean age (years) & $53.0(12.1)$ & $48.5(13.7)$ & 0.003 \\
\hline No. of males & $94(59.9 \%)$ & $92(60.1 \%)$ & 1.0 \\
\hline Body mass index $\left(\mathrm{kg} / \mathrm{m}^{2}\right)$ & $25.3(4.3)$ & $24.4(4.0)$ & 0.07 \\
\hline Primary transplant & $123(78.3 \%)$ & $114(74.5 \%)$ & 0.91 \\
\hline Duration of pretransplant dialysis (months) & $79.3(49.5)$ & $66.2(34.8)$ & 0.008 \\
\hline Mean cold ischemia time (hrs) & $15.6(6.0)$ & $17.7(8.3)$ & 0.01 \\
\hline Number of HLA mismatches & & & 0.81 \\
\hline 0 & $21(13 \%)$ & $23(15 \%)$ & \\
\hline 1 & $14(9 \%)$ & $16(11 \%)$ & \\
\hline 2 & $29(19 \%)$ & $32(21 \%)$ & \\
\hline 3 & $35(22 \%)$ & $27(18 \%)$ & \\
\hline 4 & $34(22 \%)$ & $33(22 \%)$ & \\
\hline 5 & $12(8 \%)$ & $15(10 \%)$ & \\
\hline 6 & $12(8 \%)$ & $7(5 \%)$ & \\
\hline Gender mismatch & $73(46.5 \%)$ & $81(52.9 \%)$ & 0.55 \\
\hline "Extra risk" recipients & $69(43.9 \%)$ & $49(32.0 \%)$ & 0.035 \\
\hline
\end{tabular}


Table 2. Donor demographics.

\begin{tabular}{|c|c|c|c|}
\hline & ST group & NST group & $P$ value \\
\hline Mean age (years) & $52.3(16.3)$ & $46.8(15.9)$ & 0.003 \\
\hline No. of males & $81(52.3 \%)$ & $78(51.3 \%)$ & 0.91 \\
\hline Body mass index $\left(\mathrm{kg} / \mathrm{m}^{2}\right)$ & $26.2(4.8)$ & $25.0(4.9)$ & 0.033 \\
\hline Any relevant comorbidity & $79(51.0 \%)$ & $82(53.9 \%)$ & 0.65 \\
\hline Cause of death & & & 0.28 \\
\hline Intracerebral bleeding & $93(59 \%)$ & $74(48 \%)$ & \\
\hline Hypoxia & $27(17 \%)$ & $30(20 \%)$ & \\
\hline Cardiovascular & $17(11 \%)$ & $21(14 \%)$ & \\
\hline Trauma & $13(8 \%)$ & $24(16 \%)$ & \\
\hline Other & $7(4 \%)$ & $4(3 \%)$ & \\
\hline $\begin{array}{l}\text { Median length of ICU stay before } \\
\text { explantation (days) }\end{array}$ & $4(\mathrm{IQR} 2$ to 8$)$ & $3(\mathrm{IQR} 2$ to 8$)$ & 0.99 \\
\hline $\begin{array}{l}\text { Median donor serum } \\
\text { creatinin (umol/1) at explantation }\end{array}$ & $\begin{array}{c}0.90 \\
\text { (IQR } 0.63 \text { to } 1.30)\end{array}$ & $\begin{array}{c}0.90 \\
\text { (IQR } 0.70 \text { to } 1.25)\end{array}$ & 0.96 \\
\hline
\end{tabular}

Table 3. Clinical results in the two groups.

\begin{tabular}{lccc}
\hline & $\begin{array}{c}\text { ST group } \\
(\mathrm{n}=157)\end{array}$ & $\begin{array}{c}\text { NST group } \\
(\mathrm{n}=153)\end{array}$ & P value \\
\hline Urinary tract infection & $68(43.3 \%)$ & $61(40.1 \%)$ & 0.65 \\
Ureteric leakage & $13(8.3 \%)$ & $9(5.9 \%)$ & 0.51 \\
Ureteric stenosis & $2(1.3 \%)$ & $2(1.3 \%)$ & 1.0 \\
Hematoma & $9(5.7 \%)$ & $11(7.2 \%)$ & 0.65 \\
Wound infection & $11(7.0 \%)$ & $17(11.2 \%)$ & 0.24 \\
Acute Rejection & $36(22.9 \%)$ & $53(34.6 \%)$ & 0.024 \\
\hline
\end{tabular}

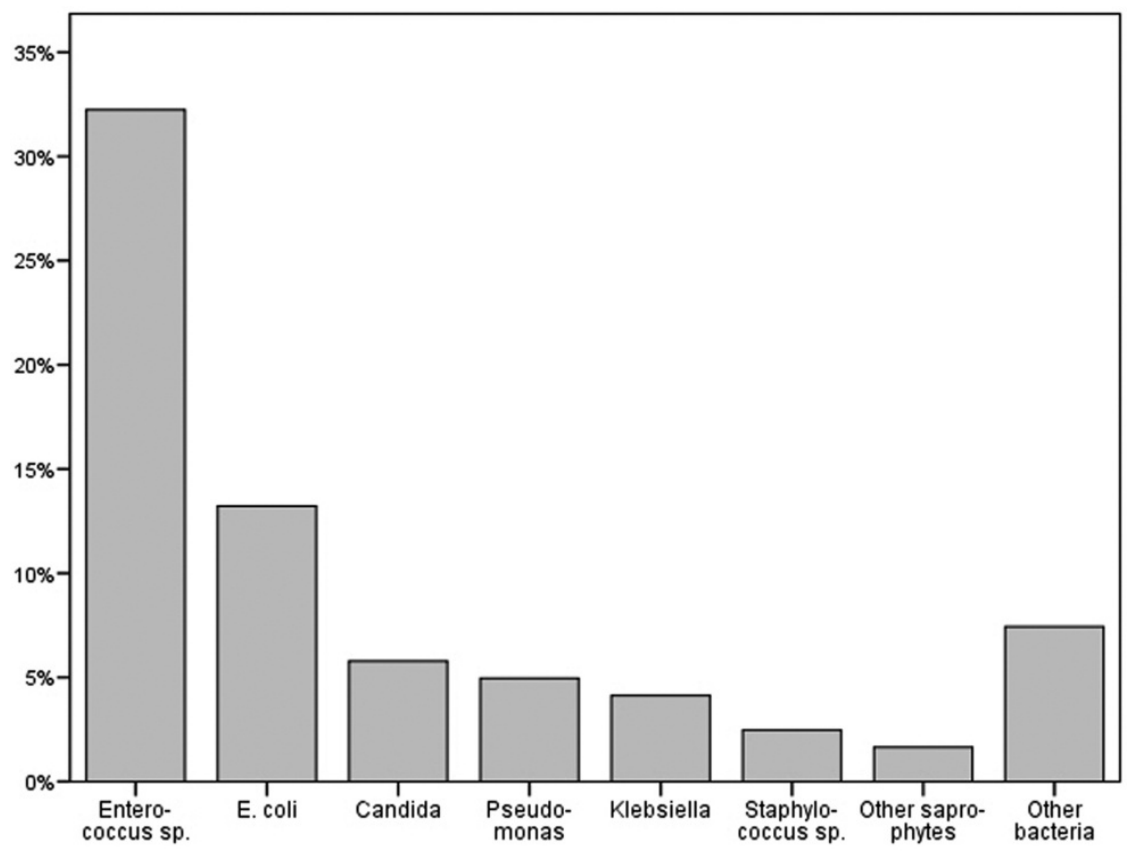

Fig. 1. Microbial species cultures from 129 recipients having clinical symptoms of UTI.

followed for at least one year. There was no significant difference between the stented (ST) and non-stented (NST) groups with respect to underlying kidney disease, body mass index (BMI), gender or HLA mis- matches. The patients from the ST group were older, the cold ischemia time was longer and these patients were dialysed longer before transplantation. Donor characteristics were summarized in Table 2. There was 
Table 4. Results of multivariate regression analyses of predictors for UTI.

\begin{tabular}{|c|c|c|c|c|}
\hline Variable & $\begin{array}{l}\text { Coefficient in Initial } \\
\text { regression model }\end{array}$ & $\mathbf{P}$ value & $\begin{array}{l}\text { Coefficient in final } \\
\text { regression model } \\
\text { (with } 95 \%-C I)\end{array}$ & P value \\
\hline Age (per year increase) & 0.998 & 0.93 & - & \\
\hline Gender (male vs. female) & 0.395 & 0.002 & $0.40(0.23$ to 0.70$)$ & 0.001 \\
\hline BMI (per kg/m²) & 1.005 & 0.88 & - & \\
\hline Diabetes & 1.0 & 1.0 & - & \\
\hline "Extra risk" recipients & 1.625 & 0.33 & $1.68(0.95$ to 2.97$)$ & 0.077 \\
\hline $\begin{array}{l}\text { Duration of pretrans-plant dialysis } \\
\text { (per month increase) }\end{array}$ & 0.998 & 0.59 & - & \\
\hline Duration of surgery (per minute increase) & 1.001 & 0.75 & - & \\
\hline Urinary stenting & 1.169 & 0.62 & - & \\
\hline Tacrolimus & 0.986 & 0.964 & - & \\
\hline Cold ischemia time (per minute increase) & 0.980 & 0.307 & - & \\
\hline
\end{tabular}

Explanatory power of the final model was limited, as Nagelkerke's R2 was 0.08.

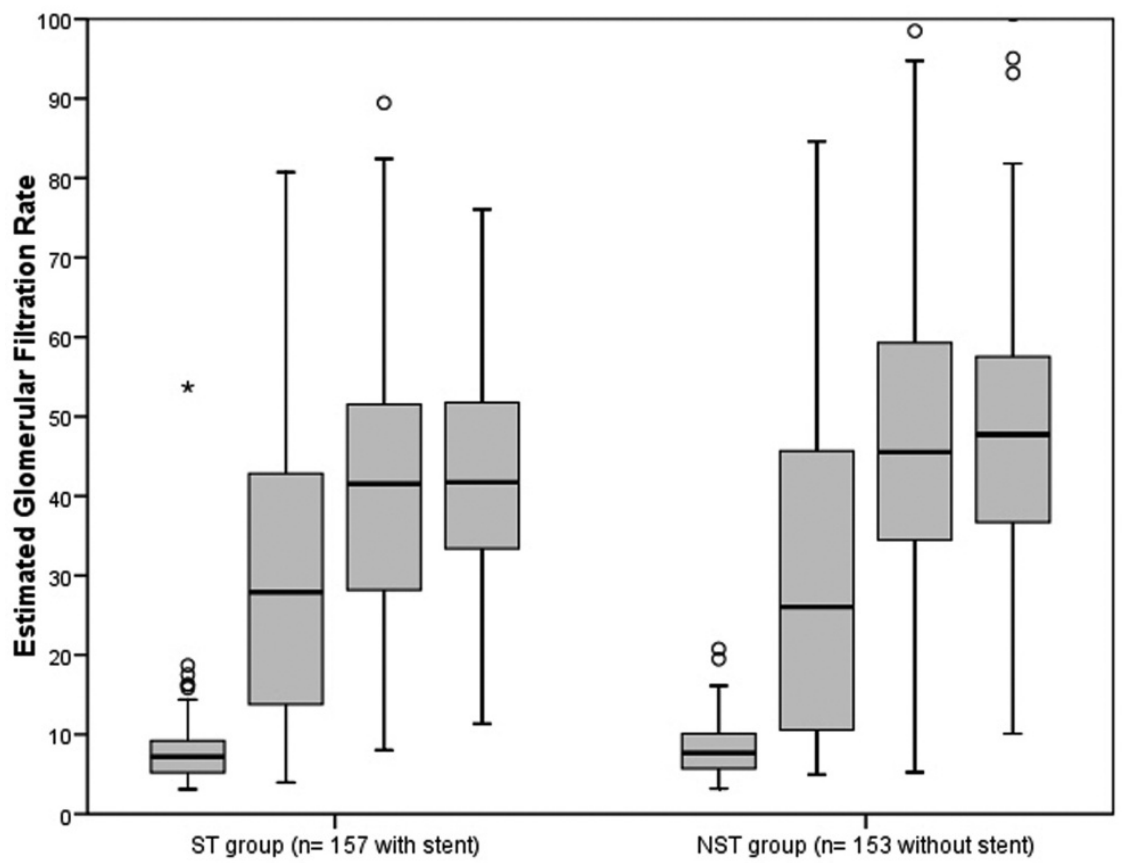

Fig. 2. Recipient eGFR (in $\mathrm{ml} / 1.73$ $\mathrm{m}^{2}$ ) at transplantation and after 1,4 and 52 weeks in the two groups. also no significant difference with regard to gender, relevant co-morbidities, cause of death, median length of ICU stay or kidney function. However, donors for stented group were older and their BMI was higher. The mean incidence of diabetes was $12.9 \%$.

One hundred twenty-nine infection episodes of urinary tract infections were diagnosed in 310 (41.6\%) recipients. The rate of UTI at three months was similar in the ST group compared to NST group (43.3\% vs. $40.1 \%)$, but without reaching significance $(\mathrm{p}=0.65)$. There was no graft loss as a result of stent-related infectious complications. Figure 1 depicts the causative pathogens of UTI.

The overall rate of urinary tract complications in the two groups were also summarized in Table 3. Anastomotic stenosis rate $(1.3 \%)$ was similar in the NST versus the ST group, urinary leakage occurred in $6.8 \%$ of all recipients, $8.3 \%$ in ST- vs. $5.9 \%$ in NST group, respectively. We observed fewer episodes of acute rejection in ST group $(22.9 \%$ vs. $34.6 \%, \mathrm{p}=$ $0.024)$. Wound infection occurred in $7 \%$ vs. $11.2 \%$ of patients (ns). In multivariate analysis (Table 4) the following categorical variables had no impact on the rate of UTI: age at transplantation, diabetes mellitus, BMI, duration of pretransplant dialysis, duration of surgery and cold ischemia time. However, female gender significantly $(\mathrm{p}<0.001)$ affected the incidence of urinary tract infection $(54.0 \%$ vs. $33.5 \%$, relative risk $1.4,95 \%$ CI 1.2 to 1.8$)$. Graft function did not differ significantly between the two groups of recipients (Fig. 2).

\section{DisCUSSION}

Renal transplantation is a widely accepted treatment for patients with end-stage kidney disease. Despite of well established surgical technique and a continuous 
improvements in patient and graft survival over the past two decades, the rate of urinary tract complications remains still considerable common and may vary between 2-15\% [12, 13]. These include urinary leak, obstruction, stenosis, necrosis and vesicoureteral reflux. These complications increase morbidity, delay graft function, and occasionally may lead to graft and/or patient loss [14].

Recently, many studies, including a prospective randomized trial, advocate stenting of the ureterovesical anastomosis to reduce the rate of these complication [15-18]. Opponents counter that the stent can migrate, could have bad permeability, could contribute to postoperative pain and stone formation [19, 20]. Others advocate that stent can increase postoperative infection risk, can erode the lumen, can exacerbate longterm stricturing of the anastomosis and the use of stenting should be restricted to difficult ureterovesical anastomosis [21].

Currently, no controlled randomized study evaluated the rate of urinary tract infections with and without ureteral stent implantation, and there is no clearly defined consensus among transplant surgeons with regard to routine stenting of the vesicoureteral anastomosis during renal transplantation. Therefore, to further evaluate this issue we conducted a comparativeretrospective study to analyse the frequency of UTI in a cohort of deceased donor kidney transplant recipients who were operated either with or without Double-J placement in our center. We also investigated the influence of stenting on renal function and major ureteric complications (leakage, obstruction).

Urinary tract infection (UTI) occurred in $41.6 \%$ of our patients. The reported frequency of UTI may vary from $18 \%$ to $79 \%[1,22]$. Differences in the definition, follow-up period, immunosuppression and the use of antimicrobial prophylaxis could explain this wide range. A recent report showed that stenting of the vesicoureteral anastomosis is a predictor factor for UTI after kidney transplantation [6]. Others could not identify such an association [7-9]. Our study has also failed to demonstrate an increased risk of UTI in stented recipients.

Other factors that have been also associated with a higher risk of UTI in renal transplant recipients include female gender, age, diabetes mellitus the function of the transplanted kidney and prolonged dialysis pre-transplantation [10]. However, except female gender, none of them was independently associated with a higher risk of UTI in our study. We did also not find that advanced age would increase the risk of UTI in our renal transplant recipients. Although earlier reports have noted a higher incidence of UTI-related complications such as pyelonephritis and urosepsis [5], we did also not observe such an increase. We observed a significant decrease in acute rejection rate in the stented patient group $(22.9 \%$ vs $34.6 \%)$. One speculative explanation could be that stenting allows early decompression of the anastomosis to ensure free drainage despite mucosal oedema, although auxiliary studies could further evaluate this issue.

Previous published studies report conflicting results whether a history of diabetes increases or does not influence the renal transplant patient's risk of develop- ing a UTI $[11,12]$. Diabetic patients have been shown to have a higher incidence of significant bacteriuria therefore we expected this trend to continue after renal transplantation. However, we did not find pretransplant diabetes to be associated with an increased incidence of UTI in our renal transplant population. The lack of impact may be due to the overall low incidence of diabetic recipients $(12.9 \%)$ in our study population.

The pathogens isolated from renal transplant recipients with UTI have been previously reported to be similar to those causing UTI in the general population [23]. A renal transplant series reported recently, that Escherichia coli would be the most common uropathogen (32\%) and Enterococcus isolated in 18\% [24, 25]. Our study identified Enterococcus spp. as leading uropathogen causing UTI after renal transplantation. These observations are in correlation with the data of Alangaden et al. identifying first that Enterococcus spp. could be the predominant pathogens in UTIs in kidney allograft recipients [1].

There are some limitations of our study. First, due to retrospective comparative data analyses and relatively small number of patients we hesitate to draw firm conclusion from the observed associations. Secondary, in the first study period ureterovesical stent were rather implanted on a subjective basis when the transplant surgeon experienced an unfavourable anatomy and expected complications.

Despite these biases, we would conclude that routine use of Double-J stents for prophylactic stenting of the ureteroneocystostomy does not affect significantly the rate of urinary tract infection in deceased donor renal transplant recipient population. Whether longer duration of stenting, immunosuppression with induction therapy by multiple transplants or living donor transplantation has a further influence on incidence of UTI is still unclear. It is therefore prudent to continue monitoring possible relationship between Double-J implantation and UTI in renal transplant recipients.

\section{REFERENCES}

1. Alangaden G. Urinary tract infections in renal transplant recipients. Curr Infect Dis Rep 2007;9: 475-479.

2. de Souza RM, Olsburgh J. Urinary tract infection in the renal transplant patient. Nat Clin Pract Nephrol 2008;4: 252-264.

3. Veroux M, Giuffrida G, Corona D et al. Infective complications in renal allograft recipients: epidemiology and outcome. Transplant Proc 2008;40: 1873-1876.

4. Lyerova L, Viklicky O, Nemcova D, Teplan V. The incidence of infectious diseases after renal transplantation: a single-centre experience. Int J Antimicrob Agents 2008;31 Suppl 1: S58-S62.

5. Witzke O, Schmidt C, Kohnle M, Lütkes P, Philipp T, Heemann U. Impact of febrile infections on the long-term function of kidney allografts. J Urol 2001;166: 2048-2052.

6. Pelle G, Vimont S, Levy PP et al. Acute pyelonephritis represents a risk factor impairing long-term kidney graft function. Am J Transplant 2007;7: 899-907.

7. Tavakoli A, Surange RS, Pearson RC, Parrott NR, Augustine T, Riad HN. Impact of stents on urological complications and health care expenditure in renal transplant recipients: results of a prospective, randomized clinical trial. J Urol 2007;177: 2260-2264. 
8. Giakoustidis D, Diplaris K, Antoniadis N et al. Impact of double-j ureteric stent in kidney transplantation: singlecenter experience. Transplant Proc 2008;40: 3173-3175.

9. Hetet JF, Rigaud J, Karam G. Should double J catheter be systematically considered in renal transplantation?. Ann Urol (Paris) 2006;40: 241-246.

10. Osman Y, li-El-Dein B, Shokeir AA, Kamal M, El-Din $A B$. Routine insertion of ureteral stent in live-donor renal transplantation: is it worthwhile? Urology 2005;65: 867871.

11. Guleria S, Chahal R, Madaan S et al. Ureteric complications of renal transplantation: the impact of the double J stent and the anterior extravesical ureteroneocystostomy. Transplant Proc 2005;37: 1054-1056.

12. Heuer M, Zeiger A, Kaiser GM et al. Use of marginal organs in kidney transplantation for marginal recipients: Too close to the margins of safety? Eur J Med Res 2009;14: 1-4.

13. Ben-Meir D, Golan S, Ehrlich Y, Livne PM. Characteristics and clinical significance of bacterial colonization of ureteral double-J stents in children. J Pediatr Urol 2009;5: 355-358.

14. Davari HR, Yarmohammadi H, Malekhosseini SA, Salahi H, Bahador A, Salehipour M. Urological complications in 980 consecutive patients with renal transplantation. Int J Urol 2006;13: 1271-1275.

15. Yigit B, Tellioglu G, Berber I et al. Surgical treatment of urologic complications after renal transplantation. Transplant Proc 2008;40: 202-204.

16. Dinckan A, Tekin A, Turkyilmaz S et al. Early and late urological complications corrected surgically following renal transplantation. Transpl Int 2007;20: 702-707.

17. DuBay DA, Lynch R, Cohn J et al. Is routine ureteral stenting cost-effective in renal transplantation? J Urol 2007;178: 2509-2513.

18. Goldfarb DA. Stented versus nonstented extravesical ureteroneocystostomy in renal transplantation: a metaanalysis. J Urol 2005;173: 889.

19. Mangus RS, Haag BW, Carter CB. Stented Lich-Gregoir ureteroneocystostomy: case series report and cost-effectiveness analysis. Transplant Proc 2004;36: 2959-2961.
20. Wilson CH, Bhatti AA, Rix DA, Manas DM. Routine intraoperative stenting for renal transplant recipients. Transplantation 2005;80: 877-882.

21. Praz V, Leisinger HJ, Pascual M, Jichlinski P. Urological complications in renal transplantation from cadaveric donor grafts: a retrospective analysis of 20 years. Urol Int 2005;75: 144-149.

22. Nicol DL, P'Ng K, Hardie DR, Wall DR, Hardie IR. Routine use of indwelling ureteral stents in renal transplantation. J Urol 1993;150: 1375-1379.

23. Dominguez J, Clase CM, Mahalati $\mathrm{K}$ et al. Is routine ureteric stenting needed in kidney transplantation? A randomized trial. Transplantation 2000;70: 597-601.

24. Tolkoff-Rubin NE, Rubin RH. Urinary tract infection in the immunocompromised host. Lessons from kidney transplantation and the AIDS epidemic. Infect Dis Clin North Am 1997;11: 707-717.

25. Schmaldienst S, Dittrich E, Horl WH. Urinary tract infections after renal transplantation. Curr Opin Urol 2002;12: 125-130.

26. Renoult E, Aouragh F, Mayeux D et al. Factors influencing early urinary tract infections in kidney transplant recipients. Transplant Proc 1994;26: 2056-2058.

27. Rice JC, Peng T, Kuo YF et al. Renal allograft injury is associated with urinary tract infection caused by Escherichia coli bearing adherence factors. Am J Transplant 2006;6: 2375-2383.

Received: November 13, 2009 / Accepted: December 15, 2009

Address for correspondence:

Zoltan Mathe, M.D., Ph.D.

Department of General-, Visceral- and Transplantation Surgery

University Hospital of Essen

Hufelandstrasse 55, 45122 Essen, Germany

Phone: $\quad+49$ (201) 72384083

Fax: $\quad+49(201) 7231137$

E-mail: zoltan.mathe@uk-essen.de 